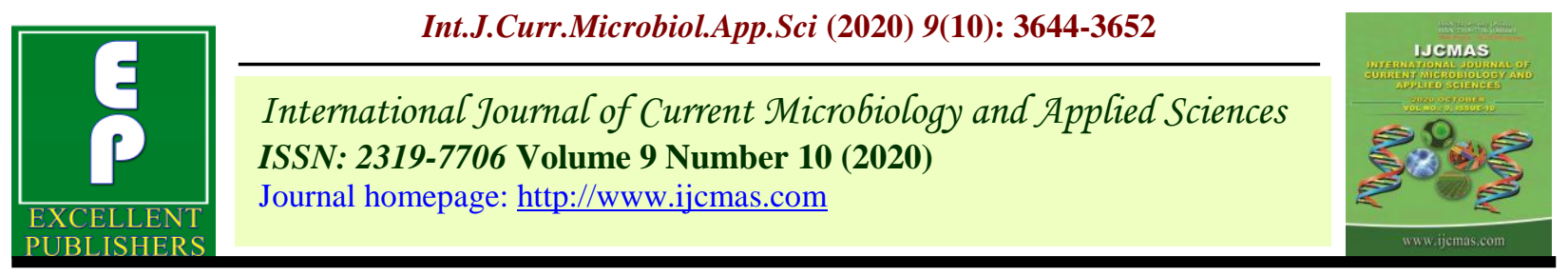

Original Research Article

https://doi.org/10.20546/ijcmas.2020.910.422

\title{
Comparative Analysis of Rice Bran Bioactive Metabolites across Diverse Rice Genotypes of Chhattisgarh
}

\author{
Girish Chandel $^{1 *}$, Renu Kushwah ${ }^{1}$, Anjali Hathile ${ }^{1}$, \\ Rashmi Upadhyay ${ }^{1}$ and Dharmendra Khokar ${ }^{2}$ \\ ${ }^{1}$ Department of Plant Molecular Biology and Biotechnology, ${ }^{2}$ Department of Plant \\ Physiology, Agriculture Biochemistry \& MAPs, College of Agriculture, Indira Gandhi Krishi \\ Vishwavidyalaya, Raipur, Chhattishgarh, India, 492012 \\ *Corresponding author
}

\begin{tabular}{|c|c|}
\hline & A B S T R A C T \\
\hline & Rice bran is a host of diverse array of bioactive metabolites such as Tocopherols and $\gamma$ - \\
\hline & $\begin{array}{l}\text { oryzanol with a potential health benefits. The substantial variation in bran composition of } \\
\text { these biomolecules ledus to investigate variation in oil content, } \gamma \text {-oryzanol and } \alpha \text { - }\end{array}$ \\
\hline $\begin{array}{l}\text { Crude rice bran oil, } \\
\alpha \text {-Tocopherol, } \gamma \text { - } \\
\text { oryzanol }\end{array}$ & $\begin{array}{l}\text { Tocopherol content in bran of } 12 \text { diverse rice genotypes. Among the tested cultivars, the } \\
\text { oil content, } \gamma \text {-oryzanol and } \alpha \text {-Tocopherolin bran showed the high variation ranged from } \\
13.52-21.62 \%, 0.82-2.92 \% \text { and } 132.2-520.5 \mu \mathrm{g} / \mathrm{g} \text {, respectively. The higher content of oil }\end{array}$ \\
\hline Article Info & $\begin{array}{l}\text { was found in Safri } 17(21.62 \%) \text {, while Danteshwari exhibited higher mean values of } \gamma \text { - } \\
\text { oryzanol and } \alpha \text {-Tocopherol content }(2.92 \% \text { and } 520.5 \mu \mathrm{g} / \mathrm{g}) \text {. Correlation studies revealed }\end{array}$ \\
\hline $\begin{array}{l}\text { Accepted: } \\
\text { 26 September } 2020 \\
\text { Available Online: } \\
10 \text { October } 2020\end{array}$ & $\begin{array}{l}\text { that the oil content was significantly negatively correlated with } \gamma \text { oryzanol while a } \gamma \text { - } \\
\text { oryzanol and } \alpha \text {-Tocopherol was found to be positively correlated. The variation found } \\
\text { suggests that he characterization of favorable ratios of oil and } \gamma \text { oryzanol content } \\
\text { particularly in Safri } 17 \text { and Danteshwari can be a milestone in identification of potential } \\
\text { donor in the crop improvement programmes. }\end{array}$ \\
\hline
\end{tabular}

\section{Introduction}

Rice is one of the major cereal crops and primary source of calories for half of the world's population, especially for Asian countries. The slogan 'Rice is Life' is more appropriate for India as this crop plays a pivotal role in national food security and is a means of livelihood for millions of rural households (Umadevi et al., 2010). Polished white rice is the major product, with rice milling yields of $65-70 \%$ and other by- products consisting of $20 \%$ rice husk and 8$12 \%$ rice bran (Hoed et al., 2006).Rice bran is produced from the outer layer of brown rice and is an excellent source of lipids ranging from $12 \%$ to $22 \%$ oil, especially unsaturated fatty acids. It also contains high valued protein $(15 \%)$ and nutritional dietary fiber (50\%) like beta-glucan, pectin and gum. In addition to phytonutrients, rice bran contains vitamins and minerals (Chatha et al., 2006). Rice bran oil (RBO) is extracted from the ricebran and is a uniquely rich source of 
commercially-important

bioactive phytochemicals used in nutrition, pharmacy and cosmetics (Mariod et al., 2014). RBO is rich in unsaponifiable fraction (unsap 4.2\%) which includes antioxidants and micronutrients, like vitamin $\mathrm{E}$ complexes such as tocopherols and tocotrienols, gamma oryzanol, phytosterols, polyphenols and squalene (Raghuram and Rukmini, 1995).

The utilization of RBO has increased considerably in Western countries due to its well-known wealth of phytochemicals and its remarkable stability at high temperature (Cheruvanky, 2006).Gamma-oryzanol $(\gamma$ Oryzanol) derivatives in particular is the most important phytochemical components of RBO which is present at 13-20 times (w/w) greater content in rice bran than total tocopherols and tocotrienols (Bergman, 2003). $\gamma$-oryzanol is mainly composed of trans-ferulic acid esters (trans-hydroxycinnamic acid) and phytosterols (sterols and triterpenic alcohols) such as cycloartenol, $\beta$-sitosterol, 24methylenecycloartenol, and campesterol (Lerma-Garcia et al., 2009). Ten fractions of oryzanolisomers from crude rice bran have been successfully isolated and identified using reverse-phase HPLC (Xu and Godber, 1997). Oryzanol is antioxidant compound and is associated with decreasing blood cholesterol levels in humans and animals along with antiinflammatory (Akihisa et al., 2000) and antitumoractivities (Yasukawa, 1998; Ismail et al., 1998). The other phytochemicals include vitamin $\mathrm{E}$ containing the four homologs $(\alpha ; \beta$; $\gamma$; and $\delta$ ) of tocopherols (Ts) and tocotrienols (T3s) (Shin and Godber, 1994). Historically $\alpha$ -tocopherol has been considered the vitamin$\mathrm{E}$ homolog of greatest value due to its high level of physiological activity. It lowers the risk of cancer formation and coronary heart diseases ${ }^{15}$.

In addition to these putative health benefits, the antioxidants of RBO have a potential use as additives to improve the storage stability of foods (Mervyn, 1994). The above concept was objectified in the present study with the hypothesis of rice bran biomolecule exhibiting biochemical variation across diverse rice cultivars that are indigenous to Chhattisgarh state of India.

\section{Materials and Methods}

Rice bran was isolated from twelve diverse rice genotypes most of them belonging to Chhattisgarh state and few were globally diverse cultivars mostly used in breeding programs. The initial moisture content of the genotypes was determined and further the experimental material was oven dried at $42^{\circ} \mathrm{C}$ for 48 hours to remove the extra moisture.

\section{Grain processing}

The harvest produce was then stored as rough rice until milling process to hinder any chemical and nutritional damages. Chemicals used in present study were methanol, acetonitrile of analytical and HPLC grade obtained from Merck (Darmstad, Germany).Chemicals such as isopropanol and petroleum ether were purchased from SDFCL (Mumbai, India). The standard for unsaponifiable matter (tocopherol) anda pure standard of gamma-oryzanol (Standard compounds of oryzanols, cycloartenyl ferulate and 24-methylene cycloartanyl ferulate) were purchased from TCI (Japan). The dried paddy was shelled using Satake Rice Huller to get the brown rice.

The brown rice was then milled in triplicate set with $12 \%$ bran removal at room temperature from the brown rice using Kett Rice polisher with a timer set to one minute. Fresh rice bran was screened to pass through a $710 \mu \mathrm{m}$ aperture sieve to remove broken grains, hull fragments, paddy kernels and foreign materials. The time of polishing was 
standardized for each variety to obtain the substantial amount of bran by checking the whiteness of polished rice between 40-45 using reflectance meter.

\section{Stabilization of Rice Bran}

Immediately after the milling, the raw bran was heat stabilized at $110^{\circ} \mathrm{C}$ for 20 minutes in the hot air oven for hydrolytic degradation of lipase enzyme that causes deterioration of bran oil and is the ultimate cause of rancidity. Before further analysis, all these samples were kept in air tight bags and stored under refrigerated condition. The heat stabilization of rice bran increases its longevity and is economical \& efficient method of stabilization for obtaining the best results.

\section{Extraction of Oil}

The oil was extracted using modern Soxhlet unit, SOCS plus oil extractor (SCS-6, Pelican equipments, Chennai). The extraction beaker and cellulose micro thimbles required for extraction were provided by the company. The beakers were pre-heated at $100^{\circ} \mathrm{C}$ for $1 / 2$ an hour, cooled in desiccators and weighed. This constituted the initial weight of the beakers (W1). Two grams of bran was weighed and transferred to thimbles; the thimbles with the holder were placed in the beakers containing petroleum ether $(80 \mathrm{ml})$ which was used as extraction solvent. The machine was run at $80^{\circ} \mathrm{C}$ for 1 hour. After 1 hour, oil was extracted and collected in the beaker. To evaporate the solvent from the oil, the machine was run at $100^{\circ} \mathrm{C}$ for 15 mins and thereafter the beakers were kept in the oven to remove the remaining solvent. The beakers were cooled in desiccator chamber and weighed. The percentage of the oil was calculated by the following formula:

$\%$ of Oil $=\frac{\text { Final weight of beaker }(\text { W2) }- \text { Initial weight of beaker (W1) }}{\text { Weight of bran }}$
HPLC analysis for estimation of $\gamma$ oryzanol and $\alpha$ - tocopherol

\section{Standard preparation}

The standards for $\gamma$ - oryzanol and $\alpha$ tocopherol were prepared from commercially available chemicals. Stock solutions of $\gamma$ oryzanol and $\alpha$-tocopherol were prepared at a concentration of $1 \mathrm{mg} / \mathrm{ml}$ in HPLC grade isopropanol. The stocks were filtered using $0.45 \mu \mathrm{m}$ syringe filter. Then stocks were serially diluted two folds up to five and twelve concentrations for $\gamma$ - oryzanol and $\alpha$ tocopherol respectively. A calibration curve was generated for each standard and the regression equation was plotted for calculating the concentration of the sample.

\section{Sample preparation}

The oil samples were weighed accurately, diluted with HPLC grade isopropanol at a concentration of $1 \mathrm{mg} / \mathrm{ml}$ and filtered through $0.45 \mu \mathrm{m}$ syringe filter.

\section{Determination of $\gamma$ - oryzanol and $\alpha$ - tocopherol content}

$\alpha$-Tocopherol and $\gamma$-oryzanol components of rice bran oil were separated by reversed-phase HPLC. The HPLC system comprised of a Waters 2690 Alliance Separations Module, a Waters 2489 dual wavelength UV/Vis absorbance detector, and 415 Waters Pump. Chromatograms were recorded and processed by Empower pro software (Waters).The separation was achieved at $29^{\circ} \mathrm{C}$ on $\mathrm{C}-18$,

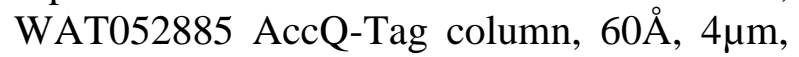
$3.9 \mathrm{~mm}$ X 150mm (Waters Pvt. Ltd, India).

The mobile phase consisted of HPLC grade Acetonitrile: Methanol (60:40 v/v) and pumped at a flow rate of $1 \mathrm{ml} / \mathrm{min}$. The injection volume was $25 \mu \mathrm{l}$ and the quantitation wavelength was set at $325 \mu \mathrm{m}$ 
and $292 \mu \mathrm{m}$ for $\gamma$ - Oryzanol and $\alpha$ Tocopherol respectively.

\section{Statistical analysis of data}

Improvement for a trait of interest i.e. rice bran oil here can be achieved bycritical analysis of its component traits and establishing interrelationship with other components along with trait of interest. In this study, correlation was established between oil content and oryzanol and between its major bioactive metabolite Oryzanol and tocopherol using excel spreadsheet program. These correlation studies give us a wider platform for concurrent improvement of these component along with trait of interest. All the experiments were carried out in triplicate set and repeated again. Replicated data were subjected to statistical analysis using WASP (Web Agri Stat Package) software (http://icargoa.res.in/wasp/ index. php). Critical difference at $1 \%$ and $5 \%$ level of significance along with average and standard error was calculated for the observed values. Data was subjected to Duncan's Multiple Range test to measure specific differences between pair of means.

\section{Results and Discussion}

\section{Crude rice bran oil content in different rice cultivars}

Results of the present study, are depicted in Table 1 entouraging average oil content $(\% \mathrm{w} / \mathrm{w})$ which is a mean of three replications with twice repetition accompanied by standard error of mean. A significant difference was seen for crude oil content among the evaluated cultivars that varied from $13.52 \%$ to $21.62 \%$. Safri17 was found to reveal highest oil content (21.62\%) whereas lowest oil content was depicted by Danteshwari cultivar (12.42\%).
Quantitative analysis of $\gamma$ - Oryzanol and $\alpha$ Tocopherol

\section{Identification and assignment of peaks}

The peak identification and assignment in HPLC chromatograms of $\gamma$ - Oryzanol was carried out by the comparison of HPLC data obtained in the present study with the published data and the peaks of standards. The four characteristic peaks for $\gamma$ - Oryzanol in the sample was obtained that were identified as: cycloartenylferulate peak 1 at $11.45 \mathrm{~min}, 24-$ methylenecycloartenylferulate peak 2 at $12.77 \mathrm{~min}$, campesterylferulate peak 3 at $14.44 \mathrm{~min}$, and $\beta$ - sitosterylferulate peak 4 at $16.53 \mathrm{~min}$ (Fig. 1). The peaks of $\alpha$ Tocopherol was identified by comparison with that of standards.

\section{Estimation of $\gamma$-Oryzanol in the oil samples}

The calibration graph obtained from $\gamma$ Oryzanol standard was linear with concentration range of $500.1-32.2 \mu \mathrm{g} / \mathrm{ml}$ with correlation coefficients $\left(R^{2}\right)$ of 0.9982.The constitution of $\gamma$-oryzanol in oil samples of diverse rice cultivars depicted the presence of four different components of $\gamma$-oryzanol. The content of $\gamma$-oryzanol significantly ranged from $0.82 \%$ to $2.92 \%$ (Table 1). Danteshwari possessed highest $\gamma$-oryzanol $(2.92 \%)$ while Kalinga and Jaldubi depicted lowest content $(0.95 \%, 0.82 \%)$.

\section{Estimation of $\alpha$-Tocopherol in the oil samples}

The composition of $\alpha$-tocopherol in the oil samples was estimated using HPLC. The calibration graph for $\alpha$-tocopherol was found to be linear over the concentration range of 4.0- $0.123 \mu \mathrm{g} / \mathrm{ml}$ with correlation coefficients $\left(R^{2}\right)$ of 0.9966 . The content of $\alpha$-tocopherol showed the significant variation among diverse rice cultivars (Table 1). The content 
ranged from 132.2-520.5 $\mu \mathrm{g} / \mathrm{g}$ with Danteshwari possessed highest $\alpha$-tocopherol content while Kalinga possessed lowest in bran oil.

\section{Correlation amongst oil content \& antioxidants}

Oil contents and $\gamma$-Oryzanol of all evaluated rice genotypes were negatively correlated with each other (Fig. 2). Cultivars such as Danteshwari which depicted the minimum oil content $(13.52 \%)$ was found to have highest $\gamma$-oryzanol and $\alpha$-tocopherol content of $2.92 \%$ and $520.5 \mu \mathrm{g} / \mathrm{g}$ respectively Whereas cultivars such as Safri-17 and Jaldubi recorded the maximum oil content $(21.62 \%$ and $20.69 \%)$ and substantially lower values for $\gamma$-oryzanol (2.07\% and $0.82 \%$ ) and $\alpha$-tocopherol (140.6 $\mu \mathrm{g} / \mathrm{g}$ and $161.8 \mu \mathrm{g} / \mathrm{g})$. A significantly positive correlation was detected between $\gamma$-oryzanol and $\alpha$-tocopherol components of estimated bran oil samples (Fig. 3). The cultivars such as Danteshwari which had maximum $\gamma$ oryzanol $(2.92 \%)$ also recorded higher values for $\alpha$-tocopherol $(520.5 \mu \mathrm{g} / \mathrm{g})$. Furthermore, Kalinga cultivar depicted the lowest value for $\gamma$-oryzanol and $\alpha$-tocopherol $(0.95 \%$ and $132.2 \mu \mathrm{g} / \mathrm{g}$ ).

The crude oil content of diverse rice genotypes most of them indigenous to Chhattisgarh varied from $13.52 \%$ to $21.62 \%$. The variability in oil content of different cultivars may be due to genetic variation which leaded to synthesis, transportation and storage of oil in the grain. The range of rice bran oil content in the current study was almost similar to the findings from Korea (Lee et al., 2002), Pakistan (Anwar et al., 2005) and Bangladesh (Absar et al., 1998). Nutritionally, among the rice cultivars tested in the present study, Safri 17 offered the highest oil content.

Table.1 Rice bran oil, $\gamma$ - oryzanol and $\alpha$-tocopherol content of different rice cultivars

\begin{tabular}{|c|c|c|c|c|}
\hline $\mathbf{S . N}$ & Sample & Oil $(\boldsymbol{\%} \pm \mathbf{S E m})$ & $\boldsymbol{\gamma}$ - Oryzanol $(\boldsymbol{\%} \pm \mathbf{S E m})$ & $\boldsymbol{\alpha}$ - Tocopherol $(\boldsymbol{\mu g} / \mathbf{g} \pm \mathbf{S E m})$ \\
\hline $\mathbf{1}$ & RRHZ- & $15.36^{\mathrm{f}} \pm 0.20$ & $1.07^{\mathrm{bc}} \pm 0.04$ & $156.2^{\text {def }} \pm 6.5$ \\
\hline $\mathbf{2}$ & Phalguna & $15.39^{\mathrm{ef}} \pm 0.26$ & $1.36^{\mathrm{bc}} \pm 0.27$ & $221.1^{\text {cde }} \pm 7.3$ \\
\hline $\mathbf{3}$ & Kalinga & $14.02^{\mathrm{g}} \pm 0.5$ & $0.95^{\mathrm{c}} \pm 0.12$ & $132.2^{\mathrm{f}} \pm 7.4$ \\
\hline $\mathbf{4}$ & Danteshwari & $13.52^{\mathrm{g}} \pm 0.05$ & $2.92^{\mathrm{a}} \pm 0.06$ & $520.5^{\mathrm{a}} \pm 5.2$ \\
\hline $\mathbf{5}$ & Basmati 8 & $16.51^{\mathrm{e}} \pm 0.17$ & $1.20^{\mathrm{bc}} \pm 0.12$ & $200.7^{\mathrm{def}} \pm 14.0$ \\
\hline $\mathbf{6}$ & IR-64 & $16.64^{\mathrm{e}} \pm 0.16$ & $1.20^{\mathrm{bc}} \pm 0.02$ & $265.7^{\mathrm{bc}} \pm 6.5$ \\
\hline $\mathbf{7}$ & TN-1 & $19.5^{\mathrm{cd}} \pm 0.07$ & $1.45^{\mathrm{bc}} \pm 0.05$ & $231.6^{\mathrm{bcd}} \pm 3.2$ \\
\hline $\mathbf{8}$ & Mahamaya & $18.16^{\mathrm{d}} \pm 0.26$ & $1.62^{\mathrm{b}} \pm 0.38$ & $300.5^{\mathrm{b}} \pm 13.6$ \\
\hline $\mathbf{9}$ & Karma Mahsuri & $19.25^{\mathrm{c}} \pm 0.10$ & $1.38^{\mathrm{bc}} \pm 0.18$ & $275.7^{\mathrm{bc}} \pm 7.6$ \\
\hline $\mathbf{1 0}$ & Kranti & $20.64^{\mathrm{b}} \pm 0.36$ & $1.20^{\mathrm{bc}} \pm 0.05$ & $238.3^{\mathrm{bcd}} \pm 3.8$ \\
\hline $\mathbf{1 1}$ & Jaldubi & $20.69^{\mathrm{ab}} \pm 0.57$ & $0.82^{\mathrm{c}} \pm 0.34$ & $161.8^{\mathrm{def}} \pm 5.7$ \\
\hline $\mathbf{1 2}$ & Safri-17 & $21.62^{\mathrm{a}} \pm 0.32$ & $2.07^{\mathrm{bc}} \pm 0.22$ & $520.6^{\mathrm{a}} \pm 6.2$ \\
\hline & Max & $21.62^{\mathrm{a}} \pm 0.22$ & $2.92^{\mathrm{a}} \pm 0.05$ & $132.2^{\mathrm{f}} \pm 8.5$ \\
\hline & Min & $13.52^{\mathrm{g}} \pm 0.04$ & $0.82^{\mathrm{c}} \pm 0.22$ & 14.9 \\
\hline & CV $(\%)$ & 4.0 & 31.76 & 100.4 \\
\hline & CD $(0.01)$ & 2.12 & 0.96 & 70.12 \\
\hline & CD $(0.05)$ & 0.63 & 0.43 & 12.5 \\
\hline & Fcal & 92 & 5.68 & \\
\hline
\end{tabular}

As per Duncan's grouping means with the same letter are not significantly different, \pm represents standard error; $\mathrm{CV}=$ coefficient of variance; $\mathrm{CD}=$ critical difference; ${ }^{* * *}$ Values are significant at $1 \%$ and $5 \%$ levels 
Fig.1 Chromatograms of $\gamma$ - Oryzanol standard (A); (1- cycloartenylferulate, 2- 24methylenecycloartenylferulate and, 3 - campesterylferulate, 4 - $\beta$-sitosterylferulate) $\gamma$ - Oryzanol of crude oil of diverse rice genotypes (B)
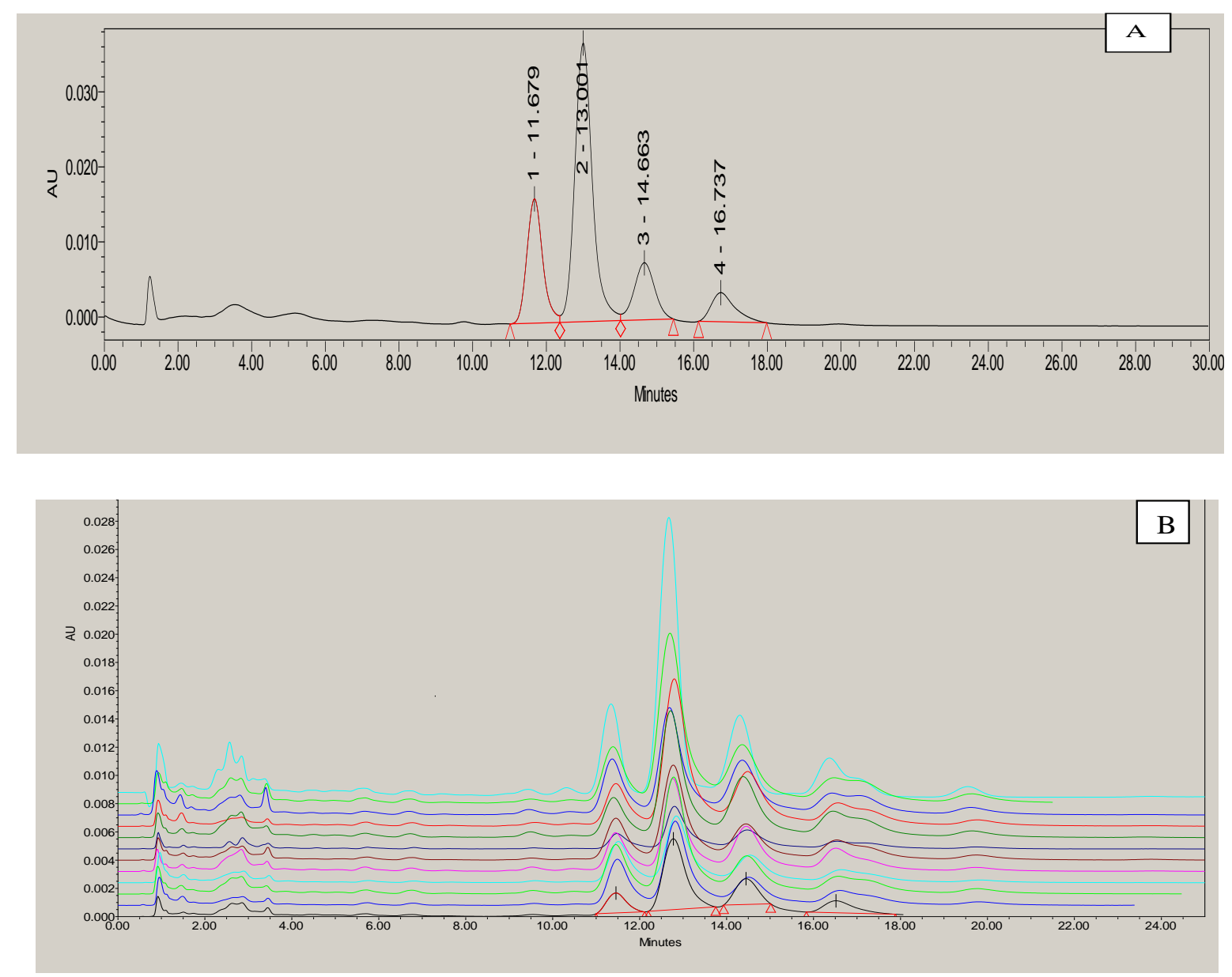

Fig.2 Negative relationship between oil content and $\gamma$ - Oryzanol of diverse rice genotypes

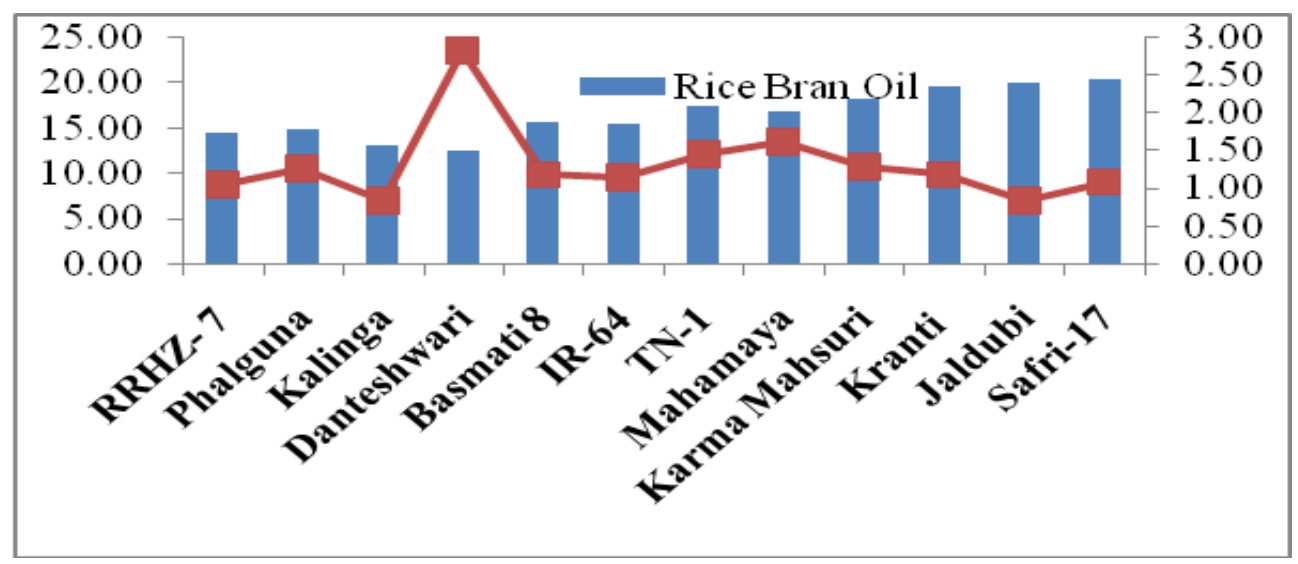


Fig.3 Positive relationship between $\gamma$ - Oryzanol and $\alpha$ - Tocopherol of diverse rice genotypes

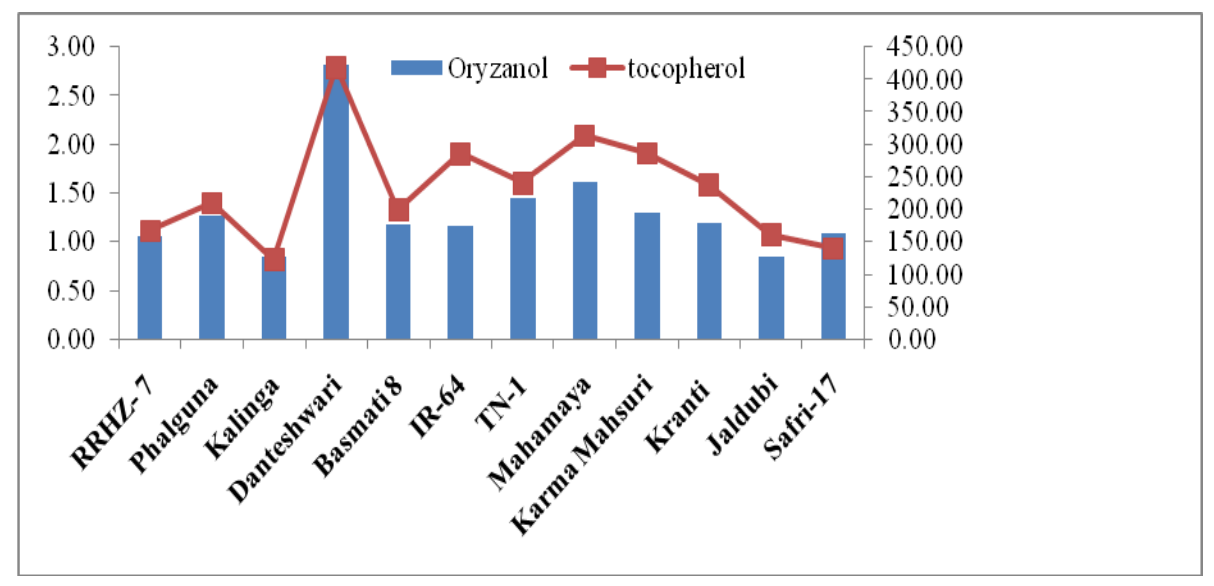

Generally, crude rice oil contains more than $2 \%$ unsaponifiable matter comprising mainly of $\gamma$-oryzanol (Yoshie et al., 2009).The antioxidant activity of $\gamma$ - oryzanol can be attributed to its structure, which includes ferulic acid with strong antioxidant activity (Nystrom et al., 2007).

In the current research, the chromatographic separations achieved through HPLC for $\gamma$ Oryzanol and its contents $(0.84 \%-2.83 \%)$ of different rice cultivars was similar to those reported by Sakunpak et al., 2014. Cumulatively, $\gamma$-oryzanol components were highest in the Danteshwari variety showing its remarkably high antioxidant characteristics and functional food capability.

Tocopherols, recognized as vitamin $\mathrm{E}$ isomers with lipophilic property (Panfili et al., 2008) was found to be maximum in Danteshwari variety $(419.6 \mu \mathrm{g} / \mathrm{g})$. Approximately $1.0 \%$ of the unsaponifiable fraction of rice bran oil is, $\alpha$-tocopherol. Studies show that $1.0 \mathrm{~g}$ of oil contains $3.0 \mathrm{mg}$ of, $\alpha$ - tocopherol (Qureshi et al., 2014)

Overall, on the basis of the amounts of highvalue bioactive components investigated such as $\alpha$-tocopherol and $\gamma$-oryzanol Danteshwari variety was found to be relatively the superior variety among others, suggesting its potential uses as a donor in the breeding program of improving economic value, as ingredients of functional foods and nutraceuticals to benefit health of consumers and promoting valueaddition.

In most of the cases, there was a negative and positive correlation between the contents of $\gamma$ oryzanol and oil of the rice brans and $\gamma$ oryzanol and $\alpha$ - tocopherol respectively. Similar results were obtained by (Mervyn, 1994). This may be attributed to the genetics of individual components and oil content. The $\gamma$-oryzanol content may be independent of the oil content while $\gamma$-oryzanol and $\alpha$-tocopherol may be a part of same biosynthetic pathway. A similar assessment has also been made in Thailand for the determination of $\gamma$-oryzanol in purple rice grains.

Similarly, variability in nutraceutical lipid content of selected rice (Oryza sativa L. spp. indica) germplasms was studied by Harakotr et al., 2019. They studied the varietal differences for oryzanol, tocopherol and other bran metabolites. These findings can support the usage of diverse rice varieties with high added-value bioactive properties.

In conclusion, on the basis of these valuable components including $\gamma$-0ryzanol and $\alpha$ tocopherol, Danteshwari was found to be the 
superior variety. While Safri 17 was found to exhibit highest oil content, this suggests the use of these rice cultivars for breeding programs, as functional foods and in nutraceutical application. Besides, it is also evident that variations may exist for the distribution of total bioactives/nutrients in relation to the rice genotype. Therefore, methods that can rapidly and reliably extract and quantify their contents in rice bran or whole rice kernel are necessary for breeding programs. Also, a strong correlation suggests that a detailed study is required to analyze the genetics that lie behind these components and oil content.

\section{Acknowledgements}

The authors wish to thank Director Research Services, Indira Gandhi Krishi Vishwavidyalaya, Raipur for providing the financial support.

\section{References}

Absar, N., Maksud, A. M. and Rahman, M. M. 1998. A comparative study on characteristics of boiled and non boiledtypes of rice bran and their oils. Bangladesh Journal of Biochemistry, 4: 43-54.

Akihisa, T., Yasukawa, K., Tamaura, T., Ukiya, M., Kimura, Y., Shimizu, N. and Takido, M. 2008. Triterene alcohol and sterol ferulates from rice bran and their antiinflammatory effects. Journal of Agricultural and Food Chemistry., 48: 2313-2319.

Anwar, F., Anwer, T. and Mahmood, Z. 2005. Methodical characterization of rice (Oryza sativa) bran oil from Pakistan. Grasas y Aceites56 Fasc., 2:125-134.

Bergman, C. J. and Xu, Z. 2003. Genotype and environment effects on tocopherols, tocotrienol and gamma-oryzanol contents of southern US rice. Cereal Chemistry Journal, 40: 446-449.

Chatha, S. A. S., Anwar, F., Manzoor, M. and
Bajwa, J. R. 2007. Evaluation of the antioxidant activity of rice bran extracts using different antioxidant assays. Grasas Aceites Sevilla, 57: 328-335.

Cheruvanky, R., 2000. Bioactives in rice bran and rice bran oil. In Phytochemical $s$ as Bioactive Agents (Ed). Bidlack, W. R.,. Omaye, S. T., Meskin,, M. S., and Tophan, D. K. W.), Florida: CRC Press, pp. 213-240

Harakotr, B., Prompoh, K., Boonyuen, S., Suriharn, B. and Lertrat, K. 2019. Variability in Nutraceutical Lipid Content of Selected Rice (Oryza sativa L. spp. indica) Germplasms. Agronomy, 9:823.

Hoed, V., Depaemelaere, G., Ayala, J., Santiwattana, P., Verhe, R. and Greyt, W., Influence of chemical refining on the major and minor components of rice brain oil. JAOCS., 83: 315-321.

Ismali, M., Al-Naqeeb, G., Mamat, W. A. and Ahmad, Z. 2010. Gamma-oryzanol rich fraction regulates the expression of antioxidant and oxidative stress related genes in stressed rat's liver. Nutrition \& Metabolism, 7, 7-13.

Kim, J. S. andGodber,J.S.2001. Oxidative stability and vitamin $\mathrm{E}$ levels increased in restructured beef roast with added rice bran oil. Journal of Food Quality,24: 1726.

Lee, H. S., Hwang, Y. H., Jang, Y. S. and Kim, M. K. 2002. Fatty Acid Composition of Rice Bran Oil and growth-promoting Effect of Rice Bran Extract and Rice Bran Oil on Bifido bacterium and Lactobacillus. Agri. Chem. Biotechnol., 45:121-124.

Lerma-García, M. J., Herrero-Martínez, J. M., Simó-Alfonso, E.F., Mendonça Carla, R. B. andRamis-Ramos, G.2009. Composition, industrial processing and applications of rice bran $\gamma$-oryzanol. Food Chemistry, 115, 389-404.

Mariod, A., Ismail, M., Abd Rahman, N. F. and Matthaus, B.2014. Stability of rice bran oil extracted by SFE and soxhlet methods during accelerated shelf life storage. Grasas Aceites.

Mervyn, L.1994. The vitamins explained simply. Bangkok: Smith, pp. 131-139. 
Nesaretnam, K., Stephen, R., Dils, R. andDarbre, P., 1998. Tocotrienols inhibit the growth of human breast cancer cells irrespective of estrogen receptor status. Lipids,33: 461-469.

Nystrom, L., Achrenius, T., Lampi, A. A. and Moreau, R. 2007. A comparison of the antioxidant properties of sterylferulates with tocopherol at high temperatures. Food Chem.,101: 947-954.

Panfili, G., Fratianni, A., Criscio, T. D. and Marconi, E. 2008.Tocol and glucan levels in barley cultivars and in pearling byproducts. Food Chem.,107: 84-91

Qureshi, A. A., Mo, H., Packer, L. and Peterson, D. M., 2014. Isolation and identification of novel tocotrienols from rice bran with hypo-cholesterolemic, antioxidant, and antitumor properties. J Agric Food Chem., 48: $3130-3140$.

Raghuram, T. C., and Rukmini C., 1995. Nutritional and biochemical aspects of the hypolipidemic action of rice bran oil: A review. Journal of American College of Nutrition, 10:593-601.

Sakunpak, A., Suksaeree, J., Pathompak, P., Charoonratana, T. and Sermkaew, N. 2014. Antioxidant individual $\gamma$ - oryzanol screening in cold pressed rice bran oil of different thairice cultivars by HPLCDPPH method. International Journal of Pharmacy and Pharmaceutical Sciences, 6: 592-598.

Shin, T. S. and Godber, J. S., 1994. Isolation of four tocopherols and four tocotrienols from a variety of natural sources by semipreparative high-performance liquid chromatography. Journal of Chromatography,678: 49-58.

Umadevi, M., Pushpa, R., Sampathkumar, K. P. and Bhowmik, D. 2010.Rice-Traditional Medicinal Plant in India. Journal of Pharmacognosy and Phytochemistry, 1: 612.

Wilson, T. A.,Nicolosi, R. J. and Woolfrey, D. 2007. Rice bran oil and oryzanol reduce plasma lipid and lipoprotein cholesterol concentrations and aortic cholesterol ester accumulation to a greater extent thanferulic acid in hypercholesterolemic hamsters. The Journal of Nutrition Biochemistry, 18: 105-112.

$\mathrm{Xu}, \mathrm{Z}$. and Godber, J.S., 1997. Purification and identification of components of $\gamma-$ oryzanol in rice bran oil. Journal of Agriculture Food Chemistry, 47: 27242728.

Yasukawa, K., Akihisa, T., Kimura, Y.,Tamaura, T. andTakido, M. 1998. Inhibitory effect of cycloartenolferulate, a component of rice bran, on tumor promotion in two stage carcinogenesis in mouse skin. Biological \& Pharmaceutical Bulletin, 21: 1072-1076.

Yoshie, A., Kanda,A., Nakamura, T., Igusa, H. and Hara, S., 2009. Comparison of gamma-oryzanol contents in crude rice bran oils from different sources by various determination methods. J Oleo Sci., 58: 511-518.

Zhimin, X., Na, H. and Samuel, G. J. 2001. Antioxidant activity of tocopherols, tocotrienols, and g-oryzanol components from rice bran against cholesterol oxidation accelerated by 2 , 20-azobis( 2 methylpropionamidine) dihydrochloride. Journal of Agriculture and Food Chemistry, 49: 2077-2081.

\section{How to cite this article:}

Girish Chandel, Renu Kushwah, Anjali Hathile, Rashmi Upadhyay and Dharmendra Khokar. 2020. Comparative Analysis of Rice Bran Bioactive Metabolites across Diverse Rice Genotypes of Chhattisgarh. Int.J.Curr.Microbiol.App.Sci. 9(10): 3644-3652.

doi: https://doi.org/10.20546/ijcmas.2020.910.422 